䁒床技術

論文受付

2014 年 2 月 18 日

論文受理

2014 年 4 月 27 日

Code No. 431

\section{脊椎照合法を用いた体幹部画像誘導放射線治療における 総合精度の検討}

\author{
中澤寿人 ${ }^{1,2}$ 内山幸男 ${ }^{2}$ 小森雅孝 ${ }^{1} \quad$ 林 直樹 $^{3}$ \\ 1 名古屋大学大学院医学系研究科 \\ 2 名古屋共立病院名古屋放射線外科センター \\ 3 藤田保健衛生大学医療科学部放射線学科
}

\section{緒 言}

近年の体幹部定位放射線治療 ${ }^{1)}($ stereotactic body radiotherapy: SBRT)はセットアップの再現性を高めて 高精度に行うために，画像誘導放射線治療 $\left.{ }^{2}\right)$ (image guided radiotherapy: IGRT)を用いている. IGRT は治療 直前に取得した透視, 静止画像, computed tomography (CT) 画像, 超音波画像などを治療計画用再構成画像 (digital reconstructed radiography: DRR)などと重ね合わ せて照合し，照射位置を定量的に確認する手法であ
る．肺癌・肝癌の SBRT に関するガイドライン1)では，呼 吸や臓器など動きの影響を受けない春椎を照合の主な 指標とするよう記載されている。しかし，治療の対象は 肺癌, 肝癌の病巣であるため, 脊椎で照合する際に病 巣にどの程度正確に照射されているかを確認することは 重要である。肺癌, 肝癌のSBRT の照射精度に関する 過去の報告では CT を使用して標的を確認する方法 ${ }^{3)}$, 金属マーカを腫瘍近傍に埋め込み腫瘍を追跡する方法4 があるが，二次元 X 線画像で標的位置を確認した報告

\title{
Assessment of Overall Spatial Accuracy in Image Guided Stereotactic Body Radiotherapy Using a Spine Registration Method
}

\author{
Hisato Nakazawa, ${ }^{1,2 *}$ Yukio Uchiyama, ${ }^{2}$ Masataka Komori, ${ }^{1}$ and Naoki Hayashi ${ }^{3}$ \\ ${ }^{1}$ Department of Radiological Sciences, Nagoya University Graduate School of Medicine \\ ${ }^{2}$ Nagoya Radiosurgery Center, Nagoya Kyoritsu Hospital \\ ${ }^{3}$ Faculty of Radiological Technology, School of Health Sciences, Fujita Health University
}

Received February 18, 2014; Revision accepted April 27, 2014

Code No. 431

\section{Summary}

Stereotactic body radiotherapy (SBRT) for lung and liver tumors is always performed under image guidance, a technique used to confirm the accuracy of setup positioning by fusing planning digitally reconstructed radiographs with X-ray, fluoroscopic, or computed tomography (CT) images, using bony structures, tumor shadows, or metallic markers as landmarks. The Japanese SBRT guidelines state that bony spinal structures should be used as the main landmarks for patient setup. In this study, we used the Novalis system as a linear accelerator for SBRT of lung and liver tumors. The current study compared the differences between spine registration and target registration and calculated total spatial accuracy including setup uncertainty derived from our image registration results and the geometric uncertainty of the Novalis system. We were able to evaluate clearly whether overall spatial accuracy is achieved within a setup margin (SM) for planning target volume (PTV) in treatment planning. After being granted approval by the Hospital and University Ethics Committee, we retrospectively analyzed eleven patients with lung tumor and seven patients with liver tumor. The results showed the total spatial accuracy to be within a tolerable range for SM of treatment planning. We therefore regard our method to be suitable for image fusion involving 2-dimensional X-ray images during the treatment planning stage of SBRT for lung and liver tumors.

Key words: stereotactic body radiotherapy (SBRT), image guided radiotherapy, spine registration, liver cancer, lung cancer

*Proceeding author 
はない.

当院では肺癌, 肝癌の SBRT に二次元 X 線画像を用 いた脊椎照合法で行っている. SBRT 治療計画では, 前後(vertical), 頭尾 (longitudinal), 左右(lateral)方向 にそれぞれ $5.00 \mathrm{~mm}, 5.00 \sim 7.00 \mathrm{~mm}, 5.00 \mathrm{~mm}$ のセッ トアップマージン(set-up margin: SM)を設定している. 本研究では, 肺癌, 肝癌のSBRT において, 二次元 X 線画像で行う脊椎照合による位置合わせの際に実際の 標的病巣の位置を評価した。 さらに, 得られた脊椎照 合と標的照合の結果を治療機掞よび IGRT 装置の幾何 学的な空間不確かさと足し合わせて, 肺癌, 肝癌の SBRT 全体の幾何学的な精度を求めた。この精度が治 療計画の SM の範囲内に含まれているかいないかを評 価し, 脊椎照合法の妥当性を検証した.

\section{1. 対象・方法}

\section{1-1 使用機器}

SBRT 用直線加速器, Novalis (BrainLAB AG, Germany) は, 患者監視装置(付属の ExacTrac)を具備している. ExacTrac は赤外線(infrared: IR)マーカと IR マーカを捉 え監視するIR カメラ追跡装置と二方向から撮影可能な $\mathrm{X}$ 線撮影装置で構成されている。治療計画用 $\mathrm{CT}$ シ ミュレータは 4 列の GE 社製 Light speed plus, 治療計 画装置は Brainscan ver. 5.31(BrainLAB AG, Germany), 体幹部固定具は CIVCO 社製のボディシェル, MED$\mathrm{TECH}$ 社製の固定天板 Hip-Fix, 吸引式クッション Vac-Lokを使用した.

\section{1-2 治療計画用 CT 撮影と DRR}

患者は仰臥位になり，背側をVac-lokで，腹側をボ ディシェルで固定された。 ボディシェル上にはIRマー カを非対称に配置したＩR マーカを非対称とする理由 は, IR カメラによる IR マーカの相互干渉を避けるため である。治療計画用 CT の撮影条件は管電圧 $120 \mathrm{kV}$, スライス厚 $1.25 \mathrm{~mm} て ゙, 1$ 回転あたり 2 秒のスロース キャンで安静呼吸下のノンヘリカルスキャン, 吸気, 呼 気停止下のヘリカルスキャンとした. DRR は安静呼吸 下で撮影した CT 画像から再構成して作成した。呼吸 性移動対策として, 腹部みぞおち部位に $5.00 \times 5.00 \mathrm{~cm}^{2}$ 程度の大きさで, 厚さ $2.00 \mathrm{~cm}$ の圧迫板を挿入し, 標的 病巣の呼吸性移動を $5.00 \mathrm{~mm}$ 以下に制限した。

\section{1-3 対 象}

2008 年 5 月から 2010 年 5 月に当院で SBRTを施行 した肺癌 83 症例と肝癌 11 症例のうち標的陰影を観察 できる肺癌 11 症例と標的と関連のある構造を確認でき
る肝癌 7 症例を対象とした. Table 1 に肺癌症例と肝癌 症例の詳細を示す，肺癌症例は $12 \mathrm{~Gy} \times 4$ 回，肝癌症例 は $5 \mathrm{~Gy} \times 10$ 回の照射を行った。各肺癌症例の病巣の位 置は S1：1 例, S6 $: 1$ 例, S9：3 例, S10：6 例であり, 下葉に集中していた。葉，中葉では，腫瘍陰影が鎖 骨や肩甲骨の陰影と重なって観察できないため, 解析 対象から除外した. Planning target volume(PTV)の最 大值は $87.3 \mathrm{~cm}^{3}$, 最小值は $3.1 \mathrm{~cm}^{3}$, 中央值は $40.4 \mathrm{~cm}^{3}$ であった，肝癌症例は手術，血管カテーテル治療の既 往があり，X線画像上で標的と関連のある金属片やリ ピオドールの血管集積部位など(標的関連構造)が観察 された症例のみであった，各肝癌症例の病巣の位置 は, $\mathrm{S} 1 / 2: 1$ 例, S3/4: 1 例, S5/8 : 1 例, S6 $: 1$ 例, $\mathrm{S} 6 / 7: 1$ 例, S8 : 2 例であり, 偏りはみられなかった. PTV の最大值は $90.2 \mathrm{~cm}^{3}$, 最小值は $26.2 \mathrm{~cm}^{3}$, 中央值 は $61.8 \mathrm{~cm}^{3}$ であった。本研究は当院臨床研究委員会お よび名古屋大学大学院医学系研究科倫理委員会の承認 （10-302）を得たうえで行われた。

\section{1-4 解析方法}

ExacTrac では治療計画用 CT から再構成された DRR と治療時に撮影する二次元 $X$ 線画像を重ね合わせて照 合する，照合方法は vertical, longitudinal, lateral 方向 の 3 軸の平行移動に加えて, 各軸に対する回転移動を 考慮した自動照合法を用いた，自動照合は肋骨，肩甲 骨など可動性のある対象を関心領域から除外し, 春椎 のみで行った，患者を固定具にセットアップし，X線画 像撮影後に自動照合を行い，当院で設定した患者セッ トアップの許容範囲 $(10.00 \mathrm{~mm}, 2.00$ 度以内)を満たし ているか確認した。許容範囲は臨床上，再現可能な範 囲とした．X 線画像と DRR 間の照合差が許容範囲内で ある場合，その差を修正した後に再度 X 線画像を取得 し，自動照合を行い，X線画像とDRR 間の照合差が $1.00 \mathrm{~mm}, 2.00$ 度以下であることを確認して，照射し た，照射後に，再びX線画像を撮影し，照射中の固定 具による患者体位の固定性を確認した。

本研究では, 照射直前(照合差が許容範囲内であるこ とを確認した) と照射後の X 線画像上で脊椎照合と標 的陰影または標的関連構造による照合(標的照合)を 行った．照合は 3 軸の平行移動のみの手動照合法で実 施された(Figure)。春椎照合と標的照合の位置の差を 真の標的照合差と定義した．治療ごとのセットアップ 位置の差(inter-fractional set-up error) は治療直前の X 線画像で評価した，治療内のセットアップ位置の差 (intra-fractional set-up error) は治療前後の X 線画像の 照合差で評価した，治療内の照合差は治療内の動きを 
Table 1 Characteristics of 11 lung cancer cases (a) and 7 liver cancer cases (b) undergoing stereotactic body radiotherapy

(a)

\begin{tabular}{cccc}
\hline \hline Case & Region & $\begin{array}{c}\text { Target size } \\
(\mathrm{mm})\end{array}$ & $\begin{array}{c}\text { PTV } \\
\left(\mathrm{cm}^{3}\right)\end{array}$ \\
\hline 1 & S1 & $23 \times 25$ & 46.4 \\
2 & S6 & $38 \times 38$ & 65.3 \\
3 & S9 & $24 \times 13$ & 37.2 \\
4 & S9 & $49 \times 37$ & 87.3 \\
5 & S9 & $31 \times 23$ & 42.8 \\
6 & S10 & $40 \times 36$ & 75.7 \\
7 & S10 & $29 \times 17$ & 3.1 \\
8 & S10 & $52 \times 41$ & 12.4 \\
9 & S10 & $20 \times 19$ & 3.2 \\
10 & S10 & $15 \times 13$ & 18.2 \\
11 & S10 & $32 \times 25$ & 40.4 \\
\hline
\end{tabular}
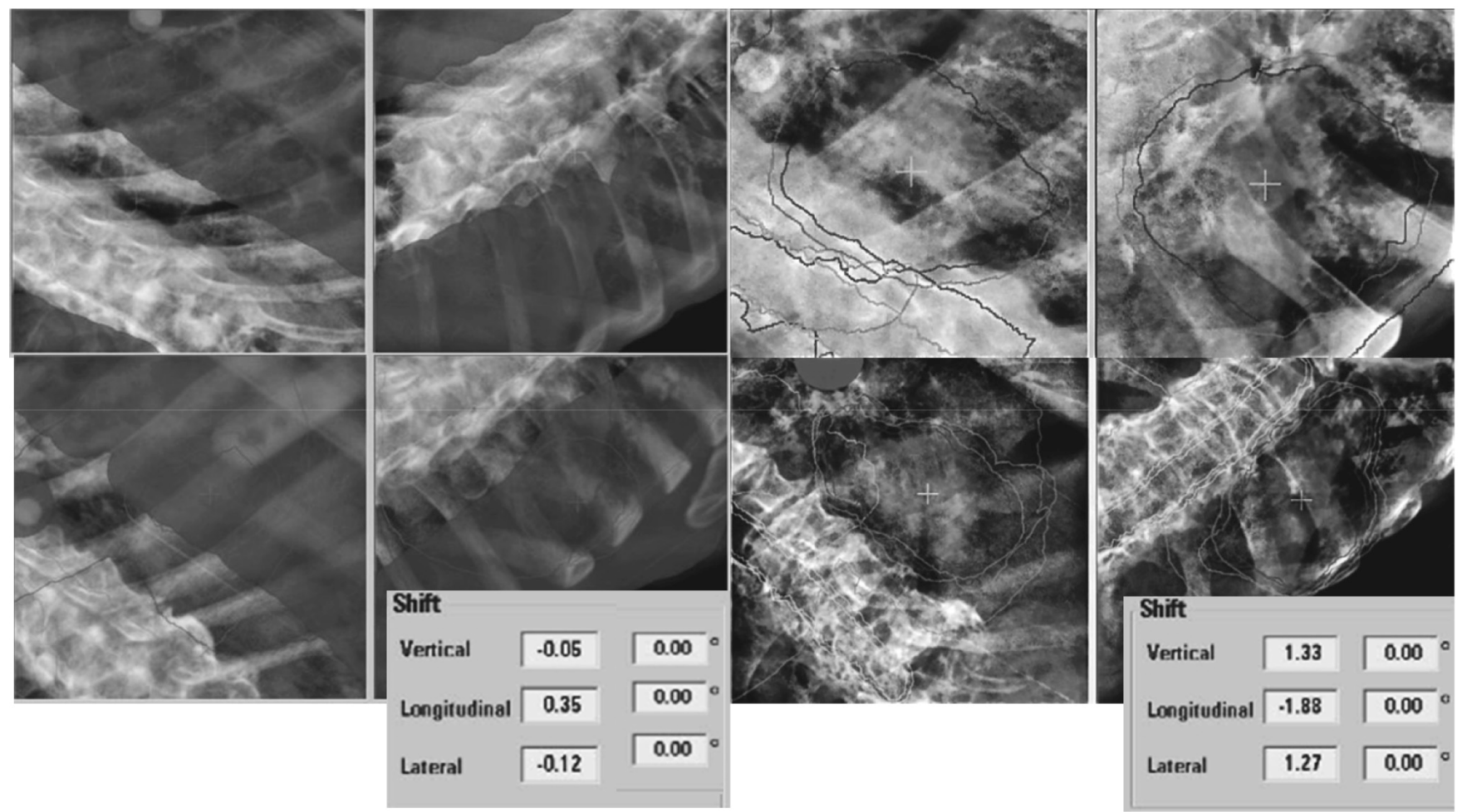

Figure Representative case of spine registration and target registration.

示しておらず,「intra-fractional set-up error」と仮定して 解析した．肺癌症例 11 例，計 44 回の照合画像と肝癌 症例 7 例, 計 70 回の照合画像で解析した。常勤の放 射線治療医はすべての照合を確認した。

\section{2. 結 果}

Table 2 に全肺癌症例, 全肝癌症例の治療ごと, 治療 内の脊椎照合差の結果と脊椎照合差と標的照合差を比 較した(真の標的照合差)結果を vertical, longitudinal,

\begin{tabular}{cccc}
\hline \hline Case & Region & $\begin{array}{c}\text { Target size } \\
(\mathrm{mm})\end{array}$ & $\begin{array}{c}\mathrm{PTV} \\
\left(\mathrm{cm}^{3}\right)\end{array}$ \\
\hline 1 & $\mathrm{~S} 3 / 4$ & $18 \times 19$ & 62.0 \\
2 & $\mathrm{~S} 5 / 8$ & $34 \times 47$ & 90.2 \\
3 & $\mathrm{~S} 6 / 7$ & $34 \times 35$ & 26.2 \\
4 & $\mathrm{~S} 8$ & $39 \times 27$ & 47.6 \\
5 & $\mathrm{~S} 8$ & $24 \times 24$ & 42.4 \\
6 & $\mathrm{~S} 1 / 2$ & $31 \times 41$ & 85.4 \\
7 & $\mathrm{~S} 6$ & $35 \times 39$ & 61.8 \\
\hline
\end{tabular}


Table 2 Inter-fractional and intra-fractional spine registration and target registration compared with spine registration (a)

\begin{tabular}{|c|c|c|c|c|c|c|c|c|}
\hline & & $\begin{array}{l}\text { Mean } \pm \text { S.D. } \\
\text { error }\end{array}$ & $\begin{array}{l}\text { Max } \\
\text { error }\end{array}$ & $\begin{array}{c}90 \% \\
\text { percentile }\end{array}$ & & $\begin{array}{l}\text { Mean } \pm \text { S.D. } \\
\text { error }\end{array}$ & $\begin{array}{l}\text { Max } \\
\text { error }\end{array}$ & $\begin{array}{c}90 \% \\
\text { percentile }\end{array}$ \\
\hline $\begin{array}{l}\text { Spine registration } \\
\text { (interfraction) }\end{array}$ & $\begin{array}{l}\text { Vertical shift } \\
\text { Longitudinal shift } \\
\text { Lateral shift }\end{array}$ & $\begin{array}{l}0.50 \pm 0.61 \\
0.47 \pm 0.41 \\
0.31 \pm 0.25\end{array}$ & $\begin{array}{l}1.21 \\
1.44 \\
0.99\end{array}$ & $\begin{array}{l}0.9 \\
0.89 \\
0.68\end{array}$ & $3 \mathrm{D}$ & $0.79 \pm 0.36$ & 2.13 & 1.44 \\
\hline $\begin{array}{l}\text { Spine registration } \\
\text { (intrafraction) }\end{array}$ & $\begin{array}{l}\text { Vertical shift } \\
\text { Longitudinal shift } \\
\text { Lateral shift }\end{array}$ & $\begin{array}{l}0.56 \pm 0.62 \\
0.52 \pm 0.40 \\
0.36 \pm 0.37\end{array}$ & $\begin{array}{l}2.68 \\
1.83 \\
1.42\end{array}$ & $\begin{array}{l}1.01 \\
0.98 \\
0.86\end{array}$ & $3 \mathrm{D}$ & $0.98 \pm 0.62$ & 3.54 & 1.65 \\
\hline $\begin{array}{l}\text { Target registration } \\
\text { compared with } \\
\text { spine registration } \\
\text { (interfraction) }\end{array}$ & $\begin{array}{l}\text { Vertical shift } \\
\text { Longitudinal shift } \\
\text { Lateral shift }\end{array}$ & $\begin{array}{l}1.09 \pm 0.95 \\
1.34 \pm 0.99 \\
0.76 \pm 0.77\end{array}$ & $\begin{array}{l}4.29 \\
4.62 \\
3.42\end{array}$ & $\begin{array}{l}2.25 \\
2.73 \\
1.78\end{array}$ & $3 \mathrm{D}$ & $2.08 \pm 1.48$ & 7.17 & 3.96 \\
\hline $\begin{array}{l}\text { Target registration } \\
\text { compared with } \\
\text { spine registration } \\
\text { (intrafraction) }\end{array}$ & $\begin{array}{l}\text { Vertical shift } \\
\text { Longitudinal shift } \\
\text { Lateral shift }\end{array}$ & $\begin{array}{c}1.49 \pm 1.10 \\
1.42 \pm 1.23 \\
0.96 \pm 0.83\end{array}$ & $\begin{array}{l}4.29 \\
5.37 \\
4.05\end{array}$ & $\begin{array}{l}2.86 \\
3.69 \\
1.74\end{array}$ & $3 \mathrm{D}$ & $2.68 \pm 1.56$ & 7.98 & 4.98 \\
\hline
\end{tabular}

(b)

$(\mathrm{mm})$

\begin{tabular}{|c|c|c|c|c|c|c|c|c|}
\hline & & $\begin{array}{l}\text { Mean } \pm \text { S.D. } \\
\text { error }\end{array}$ & $\begin{array}{l}\text { Max } \\
\text { error }\end{array}$ & $\begin{array}{c}90 \% \\
\text { percentile }\end{array}$ & & $\begin{array}{l}\text { Mean } \pm \text { S.D. } \\
\text { error }\end{array}$ & $\begin{array}{l}\text { Max } \\
\text { error }\end{array}$ & $\begin{array}{c}90 \% \\
\text { percentile }\end{array}$ \\
\hline $\begin{array}{l}\text { Spine registration } \\
\text { (interfraction) }\end{array}$ & $\begin{array}{l}\text { Vertical shift } \\
\text { Longitudinal shift } \\
\text { Lateral shift }\end{array}$ & $\begin{array}{l}0.58 \pm 0.53 \\
0.40 \pm 0.40 \\
0.41 \pm 0.31\end{array}$ & $\begin{array}{l}1.85 \\
1.99 \\
1.55\end{array}$ & $\begin{array}{l}1.22 \\
0.99 \\
0.83\end{array}$ & $3 \mathrm{D}$ & $0.93 \pm 0.65$ & 3.13 & 1.78 \\
\hline $\begin{array}{l}\text { Spine registration } \\
\text { (intrafraction) }\end{array}$ & $\begin{array}{l}\text { Vertical shift } \\
\text { Longitudinal shift } \\
\text { Lateral shift }\end{array}$ & $\begin{array}{l}0.54 \pm 0.55 \\
0.57 \pm 0.62 \\
0.40 \pm 0.42\end{array}$ & $\begin{array}{l}3.33 \\
4.41 \\
2.24\end{array}$ & $\begin{array}{l}1.10 \\
1.03 \\
0.90\end{array}$ & $3 \mathrm{D}$ & $0.98 \pm 0.87$ & 5.96 & 1.76 \\
\hline $\begin{array}{l}\text { Target registration } \\
\text { compared with } \\
\text { spine registration } \\
\text { (interfraction) }\end{array}$ & $\begin{array}{l}\text { Vertical shift } \\
\text { Longitudinal shift } \\
\text { Lateral shift }\end{array}$ & $\begin{array}{c}1.25 \pm 1.24 \\
2.74 \pm 2.07 \\
1.81 \pm 2.07\end{array}$ & $\begin{array}{r}5.51 \\
10.36 \\
15.43\end{array}$ & $\begin{array}{l}2.85 \\
5.49 \\
4.19\end{array}$ & $3 \mathrm{D}$ & $4.06 \pm 3.22$ & 19.38 & 7.47 \\
\hline $\begin{array}{l}\text { Target registration } \\
\text { compared with } \\
\text { spine registration } \\
\text { (intrafraction) }\end{array}$ & $\begin{array}{l}\text { Vertical shift } \\
\text { Longitudinal shift } \\
\text { Lateral shift }\end{array}$ & $\begin{array}{l}1.58 \pm 1.37 \\
2.30 \pm 1.96 \\
1.22 \pm 1.01\end{array}$ & $\begin{array}{r}6.94 \\
10.48 \\
5.05\end{array}$ & $\begin{array}{l}3.48 \\
4.86 \\
2.77\end{array}$ & $3 \mathrm{D}$ & $3.42 \pm 2.14$ & 13.55 & 6.59 \\
\hline
\end{tabular}

3D shows the root mean squares of the vertical, longitudinal and lateral vectors.

大きく, 最大差も肺癌症例の $5.00 \mathrm{~mm}$ 程度と比較して, 肝癌症例で $15.00 \mathrm{~mm}$ 程度と約 3 倍の差が観察された。

\section{3. 考 察}

\section{3-1＼cjkstart脊椎照合と腫瘍または腫瘍関連構造による照 合の比較}

脊椎照合と標的照合の照合差の平均は治療ごとおよ び治療内ともに肺癌症例では $1.50 \mathrm{~mm}$ 以内であった が, 肝癌症例では $3.00 \mathrm{~mm}$ 程度と肺癌症例の 2 倍近い
変位を示した。また，肝癌症例で脊椎照合と標的照合 間の最大差が観察され, 前後方向に $6.94 \mathrm{~mm}$, 頭尾方 向に $10.48 \mathrm{~mm}$, 左右方向に $15.43 \mathrm{~mm}$ であった. しか し, この場合も clinical target volume(CTV)はPTV内 に含まれており，SMに加えて, internal margin(IM)が 治療計画で適切に考慮されていた，肺は胁骨と胸郭， 胸膜に覆われているため, 固定具および腹部の圧迫に よって，その動きを制限することが可能である。一方， 肝臓は肋骨に完全に覆われていないため，呼吸性移動 
Table 3 Synthesis of each accuracy for image-guided stereotactic body radiotherapy of lung (a) and liver (b) cancer cases using the Novalis system

(a)

\begin{tabular}{lccc}
\hline \hline & $\begin{array}{c}\text { Vertical } \\
\text { shift }\end{array}$ & $\begin{array}{c}\text { Longitudinal } \\
\text { shift }\end{array}$ & $\begin{array}{c}\text { Lateral } \\
\text { shift }\end{array}$ \\
\hline $\begin{array}{l}\text { Total difference of } \\
\text { spine registration and } \\
\text { target registration...(i) }\end{array}$ & $1.85 \pm 1.45$ & $1.95 \pm 1.58$ & $1.22 \pm 1.13$ \\
$\begin{array}{l}\text { Geometrical uncertainty } \\
\text { with ExacTrac X-ray guided } \\
\text { patient setup in Novalis...(ii) }\end{array}$ & $1.36 \pm 0.32$ & $1.36 \pm 0.32$ & $1.36 \pm 0.32$ \\
$\begin{array}{l}\text { Overall accuracy resulting } \\
\text { from machine inaccuracy and } \\
\text { total setup error...(i)+(ii) }\end{array}$ & $3.21 \pm 1.49$ & $3.31 \pm 1.61$ & $2.58 \pm 1.18$ \\
$\begin{array}{l}\text { Setup margin defined } \\
\text { by treatment planning }\end{array}$ & 5.00 & $5.00-7.00$ & 5.00 \\
\hline
\end{tabular}

の影響を受けやすく，さらに固定具の特性上，患者セッ トアップ位置が頭尾方向にずれやすいため, 腹部圧迫 板で常に同じ位置を圧迫できないため, 治療計画時と 治療時で肝臓の変形を生じやすいと考えられる。その 他に, 胃や腸内のガスの量や粪便の状態, 蠕動運動も 治療計画時と治療時で異なるため, 標的の位置ずれに 影響している可能性がある.

肺癌症例の治療ごと, 治療内の脊椎照合と標的照合 の照合差の平均值と標準偏差はすべて $1.50 \mathrm{~mm}$ 以内で あった。また, 治療内の標的の位置変位は, 肺癌症例 で $2.0 \mathrm{~mm}$ 以内の症例が $80 \%, 2.00 \mathrm{~mm}$ を超える症例 が $20 \%$ ，3.00 mmを超える症例が $9 \%$ であっ。

Guckenberger ら ${ }^{3)}$ は治療機に搭載された CBCT で撮影 した 21 人の肺癌患者を全 66 回撮影し, 治療ごとの標 的と脊椎の位置を比較した。 その結果, vertical 方向に $3.30 \pm 1.10 \mathrm{~mm}$ (平均值 \pm 標準偏差), longitudinal 方向に

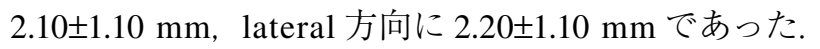
さらに治療内の標的の位置变位を 24 人の肺癌患者の治 療前後の $\mathrm{CBCT}$ (全 66 回) で評価し, $2.00 \mathrm{~mm}$ 以内の症 例が $61 \%$, $2.00 \mathrm{~mm}$ を超える症例が 39\%, $3.00 \mathrm{~mm}$ を 超える症例が $16 \%$ であったと報告している3,5．彼らの 治療ごとの結果は本研究の $1.50 \mathrm{~mm}$ より若干大きい が, 同じ傾向であった，彼らは定位ボディフレームと腹 部圧迫板を利用して患者を固定しており，われわれの 方法と類似していたためであると考えられる。長時間か けて全呼吸位相を含めて撮影する CBCTでの照合法と 比較して，われわれが用いた二次元 $\mathrm{X}$ 線画像による照 合法は任意のタイミングで X 線撮影を行い, 呼吸位相 のある一部分を捉えているだけにすぎない.しかし，分 割回数に応じて複数回(各肺癌症例で 8 回, 各肝癌症例 (b)

$(\mathrm{mm})$

\begin{tabular}{lccc}
\hline \hline & $\begin{array}{c}\text { Vertical } \\
\text { shift }\end{array}$ & $\begin{array}{c}\text { Longitudinal } \\
\text { shift }\end{array}$ & $\begin{array}{c}\text { Lateral } \\
\text { shift }\end{array}$ \\
\hline $\begin{array}{l}\text { Total difference of spine } \\
\text { registration and } \\
\text { target registration...(i) }\end{array}$ & $2.01 \pm 1.85$ & $3.58 \pm 2.85$ & $2.18 \pm 2.30$ \\
$\begin{array}{l}\text { Geometrical uncertainty with } \\
\begin{array}{l}\text { ExacTrac X-ray guided } \\
\text { patient setup in Novalis...(ii) }\end{array}\end{array}$ & $1.36 \pm 0.32$ & $1.36 \pm 0.32$ & $1.36 \pm 0.32$ \\
$\begin{array}{l}\text { Overall accuracy resulting } \\
\text { rom machine inaccuracy } \\
\text { and total setup error...(i)+(ii) }\end{array}$ & $3.37 \pm 1.88$ & $4.94 \pm 2.87$ & $3.54 \pm 2.33$ \\
$\begin{array}{l}\text { Setup margin defined by } \\
\text { treatment planning }\end{array}$ & 5.00 & $5.00-7.00$ & 5.00 \\
\hline
\end{tabular}

で 20 回)の撮影を施行したため, 標的の位置変位の大 きさを正確に評価できると考えた，だが，実際には標的 の正確な位置を評価できていなかったため, 照合差が 小さかったと考えられる.

\section{3-2 Novalis 治療における総合的な精度の推定}

SBRT では患者および標的のセットアップ精度と同様 に，治療機器の精度管理が極めて重要である。両者を 合成した全体の精度評価を行い, 治療計画の SM の設

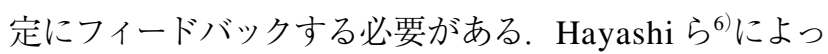
て提案された当院の Novalis システムにおける空間的不 確かさのモデルは治療機器の不確定要因を治療機の不 確定要因と照合装置の不確定要因に分類した。さらに 治療機の不確定要因は架台および寝台構造や座標系の 幾何学的な位置の不確かさに分類され，照合装置の不 確定要因はExacTrac システムに関係のあるIR カメラ 座標系と $X$ 線画像座標系の不確かさに分類された。 こ のモデルで計算された治療機器全体の幾何学的な変位と 不確かさは $1.36 \pm 0.32 \mathrm{~mm}$ であった ${ }^{6)}$. 照合全体の位置変 位と治療機器の幾何学的不確かさの合成は Novalis シス テムで治療を行う際の全体の精度となる。不確かさの合 成は二乗和平方根で計算した。 Table 3 に肺癌, 肝癌症 例の Novalis 治療における総合的な精度の計算過程を示 した．肺癌症例の Novalis 治療の合成不確かさは vertical 方向に $3.21 \pm 1.49 \mathrm{~mm}$, longitudinal 方向に $3.31 \pm 1.61 \mathrm{~mm}$, lateral 方向に $2.58 \pm 1.18 \mathrm{~mm}$ であり, 同様に肝癌症例で は vertical 方向に $3.37 \pm 1.88 \mathrm{~mm}$, longitudinal 方向に $4.94 \pm 2.87 \mathrm{~mm}$, lateral 方向に $3.54 \pm 2.33 \mathrm{~mm}$ であった. 肝癌の longitudinal 方向を除いて, この結果は当院で治 療計画時に設定している SM(vertical, longitudinal, 
lateral $)=(5.00 \mathrm{~mm}, \quad 5.00 \sim 7.00 \mathrm{~mm}, 5.00 \mathrm{~mm})$ の許容範 囲内であった。本検討は標的陰影と標的関連構造の観 察可能な限られた症例で検討したため, 系統的な誤差 要因を含んでいる可能性を否定できないが, 春椎照合 法による SM の妥当性を示すことができた。しかし，肝 癌 SBRT の SM については, 今後の更なる検討で入念 に考察していく必要があると考える.

\section{4. 結 語}

本研究は肺癌症例と肝癌症例で二次元 $X$ 線画像を用 いて，春椎照合と標的照合について検討した，春椎照 合時に標的照合が可能な症例に限定して調査したが,

Novalis システムで ExacTrac の二次元 X 線画像で脊椎 照合する方法は肺癌, 肝癌のSBRT に対して妥当であ ることを示唆した.

\section{謝 辞}

本研究にご協力いただいた，名古屋共立病院名古屋 放射線外科センタースタッフおよび同院医療技術部画 像技術室諸氏に深く感謝致します。

\section{参考文献}

1) 大西 洋, 平岡眞寛 監. 体幹部定位放射線治療-ガイドラ インの詳細と照射マニュアルー。東京：中外医学社, 2006.

2) 日本医学物理学会 QA/QC 委員会. 画像誘導放射線治療 臨床導入のためのガイドライン。医学物理 2010; 30(2): 49-53.

3) Guckenberger M, Meyer J, Wilbert J, et al. Cone-beam CT based image-guidance for extracranial stereotactic radiotherapy of intrapulmonary tumors. Acta Oncol 2006; 45(7): 897-906.

4) Shimizu S, Shirato H, Ogura S, et al. Detection of lung tumor movement in real-time tumor-tracking radiotherapy. Int $\mathrm{J}$ Radiat Oncol Biol Phys 2001; 51(2): 304-310.

5) Guckenberger M, Meyer J, Wilbert J, et al. Intra-fractional uncertainties in cone-beam CT based image-guided radiotherapy (IGRT) of pulmonary tumors. Radiother Oncol 2007; 83(1): 57-64.

6) Hayashi N, Obata Y, Uchiyama Y, et al. Assessment of spatial uncertainties in the radiotherapy process with the Novalis system. Int J Radiat Oncol Biol Phys 2009; 75(2): 549557. 